\title{
Transformation of Identities in the Mediated Landscape of the Network Society
}

\author{
Ali Simsek, Anadolu University, Turkey \\ Eylem Simsek, Turkish Air Forces, Turkey
}

\begin{abstract}
Emerging communication technologies have changed both individuals and societies dramatically. With the diffusion of digital technologies in daily life, all users have been forced to create new identities for themselves. Thus, everybody had an additional self in virtual worlds. The users started to communicate with others through their self-made identities proving that technology started to shape our lives. Sometimes this new identity has reflected the real self of individuals while some other times it has been created with no actual reference to the realities of its holders in the physical world. However, one thing is clear: Most users of virtual environments have developed multiple identities and these identities have inherently transformed who they really are. Considering that the contemporary society is an increasingly network society, human beings try to accommodate their social needs through interaction with companions in the mediated environments whom they often don't know at all. Technology plays a mediating role in this sense among people who are temporary companions but actual strangers to each other. Moreover, people think that if they can accommodate their social needs through the net characters, whether they are real or not, then they ask themselves: "Can we escape from humans who demand intimacy and find risk-free virtual buddies?" The search in this regard has even prolonged to sensitive robots as social partners. This paper discusses how this inner transformation of identity has occurred and what the future holds for communication in the mediated landscape of the network society.
\end{abstract}

Keywords: Virtual identity; Network society; Digital technologies; Mediated landscape; Social media; Computer mediated communication 


\section{Introduction}

The need for socialization is generally accepted as a basic human need. The investigation of human at the individual level is the subject of psychology, individual-society interaction is the subject of sociology, and individual-group interaction is the subject of social-psychology. All these areas of scientific inquiry suggest that communication is a key factor during the socialization process because the interactions within and between individuals are mostly defined as communication. As well known, Schramm pointed out that everyone who is interested in human behaviors should take communication into account (McQuail \& Windahl, 2005, p.11).

The new communication environments, especially network-based technologies, have changed the nature of communication. Most recently, smart phones and tablet computers are perceived to be almost an inseparable part of the body. From the shift of one-to-one communication towards one-to-many communication, culturally-shaped identities have been transformed to personally-designed identities in the virtual or digital culture. Thus, individuals have more control over their identity presentation but also more risks.

\section{Identity and Social identity}

Identity is a byproduct of the socialization process. Although a theoretical discrimination is made between "identity" and "social identity", both are the results of interaction with the environment. Social identity highlights the individual-group interactions, whereas identity is seen as more personal but not independent from the outside world. Social Identity theory suggests that group membership and social categorization have impact on how individuals evaluate the self and the others. Social identity is "the part of the individual's self-concept (self-identity) which derives from his or her knowledge of membership to a social group together with the value and emotional significance attached to it" (Tajfel, 1981, p.255).The self "is a process of social activity, constituting "I" and "me". "I" refers to the response of organism to attitudes of others, whereas "me" is the organized set of attitudes which one himself/herself assures. The concept of self contains perceptions and interactions of both within the individual and between the others. "Social self" is individual's personality within the social sphere which means "identity" (Vitak, 2008). Identity, whetherit is self or social, is acquired through interaction of the individual with the outside world. 


\section{Social Identity and Communication Relationship}

The individual-group interactions emphasize the dynamic nature of social identity. Erikson (1980) defined identity as an ongoing process of establishment and evaluation of the self-incontext. A healthy self is related to individual self-concept and adaptation to social context; which refer to developing personal and social identity respectively (cited in Walters, 2010). This means that depending upon the group you are related or belonged to, your social identity may change. Then the question becomes: Is it easy to change our social identity? If we can change our social identity via social groups, then what are the most important groups we interact? They may be family, friends, relatives, officemates, hobby groups etc. in the realphysical world.

For the communication purpose, the primary and secondary groups could be associated with the "context" of communication so the "content" of communication is not totally independent from group characteristics or social parameters. Riley and Riley (1959) underlined that human beings are not atomized individuals. Primary groups (i.e. family, friends, and relatives) and secondary groups (i.e. legal or formal relationships) determine norms, beliefs, and values of individuals. Communication as social action is dependent on primary and secondary groups in order to encode and decode messages. Individuals often assign meaning to the world under the influence of their groups. Groups make people feel more comfortable and more secure. Groups also give cues or norms to react to the events. Through a variety of social processes including communication, group standards are internalized over time (cited in McQuail \& Windahl, 2005).

The concept of social identity has been developed with the categorization studies. Categorization means having stereotypes according to the characteristics of groups. Categories serve as shortcuts during the cognitive processes. According to Tajfel (1969), categories nurture the between-group conflicts and in-group congruence. My group's and other group's thoughts lead to the expectations to increase my group's status or image and decrease the other group's status or image. Individuals are willing to catch information that supports their categories. Moreover, the categorization beliefs are so strong that even opposite cues and objective evidence exist, individuals are resistant on their misbelieves. 
Social comparison is another important concept related to constituting and monitoring social identity. Social comparison is a kind of information acquisition activity. In-group and outgroup discrimination affects comparison and evaluation often favoring the in-group. Social comparisons sometimes may lead to split from the group due to unsatisfied needs (Demirtaş, 2003).

The categorization experiment by Tajfel, Billig, Bundy, and Flament (1971) showed that grouping is easy. Even depending on the groups, namely Klee and Kandinsky group, without any logical reasoning, individuals created the perception of the self and the other. Individuals who were 14-15 years old wanted to give money to other individuals based on very limited information about their groups. Although the reason for categorization is superficial or irrelevant, individuals tended to behave unfairly in order to increase their group's interests. This means that the group norm by itself may create biased behaviors.

Humans accept or reject information depending on their prior beliefs, thoughts, information etc. In other words, the communication process (i.e. decoding the message) is not objective in terms of the context. Social identity serves like a filter. Coded and uncoded meaning could be evaluated, questioned, accepted or rejected differently due to the expectations of congruence between group norms and the message. This is clearly social confirmation, which is a result of social identity (Lord, Ross, \& Lepper, 1979; Peffley, Avery, \& Glass, 2001).

Stryker's Identity Theory underlines the importance of a specific identity compared to one's other identities like being a mother, wife or working woman (cited inWalters, 2010). Identity salience empowers identity-behavior relationships. Among the identities, one identity may be much more effective than others in shaping the behavior.

Why groups have such a power over individuals? Why individuals may reject the message even if it has objective truth? Althusser (2006) explains this issue with the concept of "ideology". Ideologies highlight the behavior which support self-image and group congruence. Belonging to a group refers to accepting that group's ideology. In this sense, ideology is defined as a kind of design system in the mind of individuals and society. The working process of ideology is connected with production processes as well as the 
phenomenon of unconsciousness. Ideology is found to be especially important for religious or ethnic categorizations (cited in Şimşek, Özer, \& Şimşek, 2012).

The incompatible information or behavior to the group has some implications like being rejected from the group, feeling lonely, loosing social support or family. Individuals need to have a place and reputation in the group, which they do not want to lose easily. Groups have a number of visible and invisible means for pressure to maintain themselves via social identities (Aslan, 2013) so that changing the social identity may not be easy or possible.

What about the self which is not congruent with social identity? Social identity is like a boundary in which the self or other social identities may not behave independently. In this context, the Johari window may be helpful to understand virtual identities. This schema divided self into four areas. They are: open area (known by self and others), hidden area (known by self and unknown by others), blind area (unknown by self and known by others) and dark area (unknown by self and unknown by others). The hidden area could be associated with the incongruent self to social identity. Self-disclosure is valid for the areas unknown by others, while self-discovery is effective for areas unknown by the self (http:/www.mindtools. com/CommSkll/JohariWindow.htm).

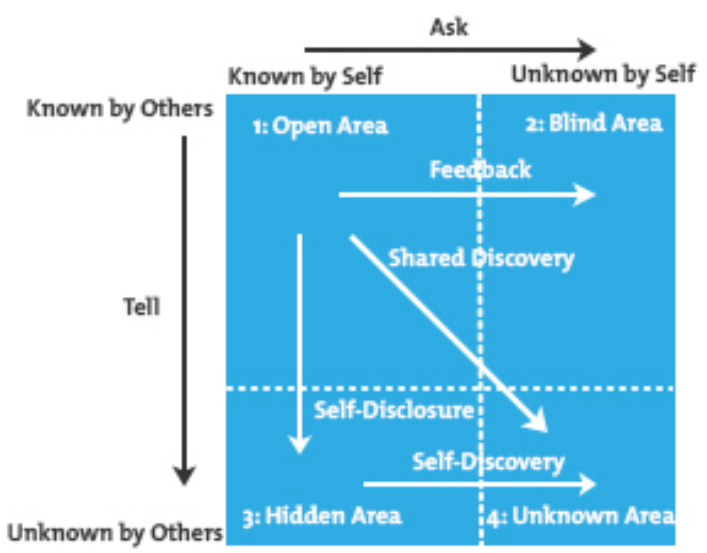

Figure 1: The Johari window

Tajfel and Turner (1979) recommended resolving identity problems via two methods: individual actions and collective actions. The first one is related to the social mobility belief system that evaluates the boundaries between social groups as permeable and flexible. One 
could change its group or ideology from a disadvantaged group to the advantaged group depending on his/her ability, desire, effort etc. This is an individual-based strategy. The second one is the social change belief system, evaluating boundaries between social groups as impermeable. Changing the group is almost impossible. Therefore, instead of individual actions, collective actions seem to be a solution for disadvantaged groups. Instead of individual-based strategies, collective strategies are important to change status quo. Generally, collective strategy is only preferred when individualistic strategy failed (Elgin, 2007, p.4).

\section{Virtual Communication and New Identities}

Turkle (2011) divided the history of technology-identity relationship into three parts: One-toone, one-to-computer, one-to-many via computers. One-to-one is traditional communication and identity acquisition. During the 1990's one-to-computer appeared to explore the information via browsers and search engines without enough interaction. With the Web 2.0 technologies during 2000's, the applications of Internet connections like Twitter, MySpace, Blogs, Wikis, YouTube, Facebook etc. as well as the forms of relationships have been dramatically changed. From one-to-one relationship to one-to-many interaction possibility lead to changing passive information users to active digital citizens (Şimşek \& Şimşek, 2013). Reading and writing practices transformed to designing and sharing (Kress, 2010, p.6).

As often mentioned, virtual communication is different from conventional communication. New technologies change the nature of relationships depending upon their features, mostly in the form of mediated communication. Main features of mediated communication can be summarized as follows (O'Reilly, 2009): (a) It changed the traditional group process;(b) It uses less non-verbal messages and body language; (c) It gives an opportunity to be anonymous; (d) It eliminates the group pressure; (e) It compensates some needs of individuals which could not normally gratified; (f) It gives individuals an opportunity to control the level or the type of the relationship. Control over the data has increased. Individuals can select individuals with whom they want to communicate, how they will communicate etc. (g) It eliminates the time and distance problems in the communication process; (h) It has user-based technological characteristics. Most of the applications were freely accessible; (i) It includes multimodal information such as text, audio, photos, videos, links, music etc; (j) It changed the 
traditionally hierarchical structure of communication. All these fundamental characteristics have had certain influences on building virtual identities.

Until recently, the role of groups that shape identity via communication has been discussed. In the new era, however, the group forms have changed. Instead of groups, new programs like Facebook, LinkedIn, and Twitter take the mediator role to shape identity with their categorization types and sub-groups. The control over the selection of the audience, which may be friends, followers, players and so on, has significant effect on identity formation or presentation. As a striking example, one may have another (virtual) husband or wife in the Second Life. Blogs may be read by everyone whereas Facebook photos could only be seen by friends, if restricted. Blogging gives opportunity to explain more things without word limitations in contrast to Twitter which has a general restriction of 140 text characters. The Twitter followers, Facebook friends, readers of blogs, or players of collaborative games are the new social groups. The messages, feedback, comments, participation, interactions, and sharingin these groups create social communication process. Thus, the form and content of communication may change depending on the type of virtual communication.

From the optimistic view of the new technologies, the pressure of groups on individuals is expected to be less in virtual environments. Participation, discussions, and debates may easily be made without negative results compared to the real life. Public sphere and ideal communication action, as suggested by Habermas, maybe achieved in virtual environments. Communication in the digital world is expected to support different identities which were freed from the capitalist boundaries. For shaping and developing identity, virtual media could serve as a new ideological platform with appropriate conditions and equal power relations. It should be questioned whether virtual ecosphere represents a real democratic platform to develop healthy identities. What about the characteristics of Internet groups that have a potential impact on identity? Are the discussions in online communities based on democratic values? If the pressure of Internet groups is similar to the pressure of real groups, healthy virtual identities cannot be created and shared.

Virtual communication has generally been designed to present your identity according tocertain categories and choices. The appropriate programs provide opportunities to determine the amount as well as the quality of submitted information. However without enough identity 
information, socialization is almost impossible, especially for social media like Facebook, Twitter, Second Life etc. Although it seems that you determine the amount and quality of the information expressing your identity throughout virtual/social communication, some of the uncontrolled data about your identity are opened to everyone. This is not only a security issue. The nature of social relationship always exposes strong information about identity. As common saying goes "Tell me your friend, I'll tell you who you are". Similar toreal-life groups, virtual groups also convey critical information about your identity. The data you control is in the open area as described in the Johari window. In contrast, uncontrolled but released data are associated with the blind area.

\section{Discrepancies between Real and Virtual Identities}

Why real and virtual identities are not the same? When two strangers meet, they usually ask to each other where they are from, what they do for living and so on. Technology-mediated communication exposes so much information including family, relatives, hobbies, group memberships, professions etc. Besides the real identity, a virtual identity is indispensable to maintain one's computerized social life. Normally, the real and virtual identities are expected to overlap. However, sometimes this is not the case. Here we are not talking only about the name, surname or password. One may present himself/herself differently in virtual media than who he/she really is in the physical world; a mixed identity is also possible.

If one uses the Internet as an alternative to real life in which he/she plans to realize her dreams or needs, there will possibly be an identity confusion. A shy, nerdy, timid individual in real world can reveal himself/herself with a completely opposite identity in the virtual world. For example, by using the disguised photos of a beautiful model and "The Water Angel Z" pseudonymity on the Internet in Turkey, a perjuring lady was able to get about 100,000 USD from a university professor on the promise to marry him (Posta Gazetesi, 2012). 


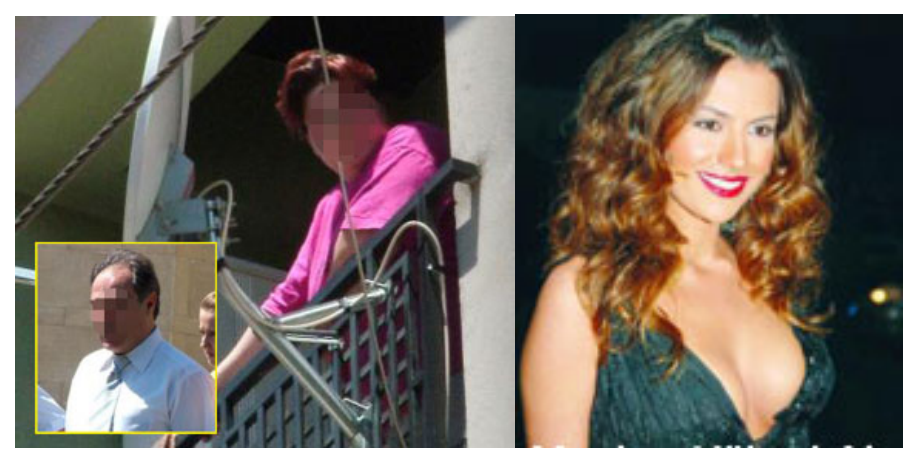

Figure 2. An example of a difference between the real (left) and the revealed (right) identities of a woman who want to marry a professor (Source: Posta Gazetesi, 2012).

Another characteristic of the technology-mediated communication is the anonymity which leads the discrepancies between various identities. Anonymity gives someone to release the blind area and dark area of the Johari window. Besides this, the eroused ID in the crowds, as used by Freud, may also explain identity variations (Arkonaç, 1993). For this reason, some parts of identity, which until now did not exhibited, may be observed. This can explain the difference between the actual identity and the virtual identity. When virtual tools or applications are used for the purpose of an individual's self-discovery and when the individual is not aware of himself/herself, some of the subconscious features may come to the surface. For example, the profiles on sites like Second Life could bring out the identity which is unknown. The uncertainty in the communication process creates the effect of train passengers, which refers to the situation that people frequently, see each other but do not really know what their actual identities are. However, sometimes individual does not explain the same information to close friends. Although identities are dynamic, they also require some consistency which train passengers could not evaluate. The boundaries of identity could be freed by Internet and retrieve a degree of relaxation.

The Internet has its own logic by using codes, signals, pixels etc. Therefore, when Internet used, the Internet-based identity automatically appears starting with an IP number. Identity is critical for the sense of self-disclosure by users and for marketing issues and security by the owners of the sites. This is true even for the use of pseudonymity. For example, "Barbie" or "slamdog" nicknames still contain some real information about the owners. Moreover, what you say or do on the Internet is important while creating identity. Pearson (2009) named this process as "identity performance" like in a theater. When bright profile photos are used and 
web designs are not fed with reliable content, the persistence of the identity can become controversial.

Depending on the type of virtual communication technologies, identity is shaped in various forms. Using Internet itself is being in a bigger and different social group, meanwhile the types of virtual communication represents owned subgroup. Facebook, Twitter, MySpace etc. create different identities within the framework of their sub-cultures. These digital identities are not independent from the real identity observed in the real word, which is not necessarily coincide with the real identities either. The reason for this situation is that the real identities are those which are not a representative of complete identities. Virtual communication could bring to surface the remaining part of the identity which is covered and cannot be seen. The conflicts between real and virtual identities may be originated from the disclosure of the identity in the technology-mediated world. Disembodied and electronically codified nature of virtual media (Pearson, 2009) can overcome the impersonalization of social identities in the real world (Demirtaş, 2003). Instead of group membership, individual approach may determine behavior and identity.

Asan opposite view, it may be proposed that different interaction structures of digital groups could shape the individual's identity. Group-mind constitutes individual identity with group identity. Identities of the individuals in the group are dependent on unusual interaction of ingroups (Hogg \& Abrams, 1988). In this context, the Internet groups may create their own thoughts and idea shaving the power to shape their digital members. It is an important research topic whether the virtual identity is in fact a secret identity or an identity emerged with the interactions of digital groups.

\section{Results of Virtual Identities}

Virtual communication brings a perception of safety. Moreover it usually offers the possibility to communicate without canceling jobs and going somewhere. This safety perception can suppress some of the requirements as well as fulfilling some other requirements. Healthy interpersonal relationships represent one of the most important reasons to resume a happy life. However, although very intensive relations are claimed in the virtual communication, there are also doubts about how real these relationships are. With virtuality dimension, the relationships lose or change their meanings. Safe distance requirements 
suppress the sense of intimacy. Therefore, many people want to go one step ahead -virtual robot applications, friends, loversand so on. (Turkle, 2011). This shows the problems regarding virtual satisfaction. Robots, as intelligent program orientations, show the erosion of the main human need, search of meaning and trying to repair it. Horkheimer (2005) offered the concept of "eclipse of reason" for this kind of situations, in which human beings fight with the nature helplessly. Individuals take a big risk to lose their contexts and roots.

The questions, whether virtual identity should be compatible with the real identity is resembled as a double-edged sword (Grohol, 2006). Identity information demands by sites could be resulted in avoidance of them. Each social media type like YouTube, Linkedln, Facebook, Twitter and so on requires different usernames and passwords. Individual's life is going on cycling between programs. Although smart phones make this process faster and easier, the effort in constituting, presenting, and maintaining identity becomes much more challenging day by day. Turkle (2011) pointed out the negative results of the computer connectivity, namely anxiety. In many cases, anxiety is caused by consistency demands to maintain the identity reputation which puts individuals under a pressure they cannot bear in the long term.

Virtual communication is not always healthy. The lack of identities brings many negative identities as lollz, internet predators or trollers. As a behavior of deviation, lolz (lol-laughing out loud) means laughing at the expense of someone else. Digital world reduces the social barriers and makes individuals more vulnerable. Users sometimes become victims. Predators are more destructive than lolz, who are often children or teen abusers. Trolling is defined to denote someone who disrupts intentionally online communication. Deviation of personality disorder or identity problems usually reflect being anonymous. Sensitive and weak points of other individuals in their real lives are investigated to harm them by whom having troubled identities on their real lives. As an example to cyberbullying behavior, a suburban wife led to their daughter's friend'ssuicide with a faked identity (http://en.wikipedia.org/wiki/Suicide_of_Megan_Meier).

Following a number of wiki scandals mostly due to a certain lack of identity, the site owners developed the concept of membership as a solution to this problem. A hierarchical structure is introduced for visitors, group members, administrators or moderators. Thus, the stratifications 
in real groups, intra-groups, and outsiders are adapted to the digital groups with different identities. This situation limits free feeling and disinhibitarory effect of online behavior. Registration system serves as a reputation system, as well as the reliability of the individuals, just as real communities. During the registration, a lot of questions may lead to disclose the personal inhibitions or identity. To overcome this problem, segmentation is performed; first short registration questions are asked, and then the users are verified by their e-mail addresses and profile questions. In other words, the digital world too needs respected and trusted identities with regard to Internet logic.

Addiction of Internet, social media or virtual worlds has become another issue with the demand of getting more pleasure. The pleasure demands disturb the identities. Although it is not easy to admit the addiction problem, news often tell us dramatic stories that a little boy or girl died because of their parent's playing 24 hours on the Internet and uncaring or not nurturing their children. It is also a common phenomenon that even the spouses or family members in the same house exchange messages through digital networks.

Sometimes the pressure of digital identities creates a need to get rid of social media or virtual media. Web 2.0 suicide tendency has recently started to spread as a new trend. A program (http://suicidemachine.org) is developed to easily close the social media accounts and delete the history. Approximately one million people are claimed to shut down their social media accounts so far. Even getting rid of the virtual/social identity is a time and labor consuming process.

\section{How to Solve Virtual Identity Problems}

Virtual identities have an agenda to eliminate some of the disadvantages of real-world problems. The relationships are classified as weak relationships and strong relationships similar to the Riley and Riley Theory in the real social context. Weak relations reflect the way of the furthest nods, and strong ones are associated with emotional engagement (Pearson, 2009).However, studies generally suggest that Internet reduces the quality of relationships in the real world due to time constraints. However, to what extent healthy relationships in virtual environments may be developed is questioned by Simone Back's dramatic story. A42 years old woman has written her suicide attempt on the Facebook. Except one friend, none of the 1082 friends gave a real response like calling police or offering help. Instead of preventing 
her suicide, some of the Internet friends even blamed her to be a liar (http://www.dailymail. co.uk/news/article-1344281/Facebook-suicide-None-Simone-Backs-1-082-online-friendshelped-her.html)

Instead of network friends, the perception of online theater performers is extremely uncomfortable. The digital life brings old Venice life with masks; individuals could both hide themselves and create another identity with their masks at the same time. It is like Halloween parties. The virtual identities are similar to the masks that people select and wear to hide their known identities. During the masquerade or virtual communication everyone could see each other but not know who actually they are. Nobody could continue his/her life with masks. Masquerades end and individuals return to their realities at the end of the party. However, it appears that communication with virtual identities in the mediated landscape of the network society will continue at a global scale.

Destroyed barriers between real and digital worlds may create conflict in the meaning as well as in identities (Turkle, 2011). Especially for children, the distinction between the real life and the dream world is already uncertain. This flue context affects responses of them in unpredictable ways. It is not easy to claim that identities used in the digital world do not affect the real life. Thoughts affect behavior and behaviors affect thoughts. People in the virtual communication environments tend to act like someone else with various or multiple identities and this situation may influence individual behavior pattern in the real life. If more positive characteristics and skills acquired, less problems could be expected. However, the effect of a troubled social media profile and his/her behaviors in real life should seriously be questioned.

The ways for building healthy virtual identities may be explained by two approaches: robust real identity and sufficient digital literacy. Since the ancient times, the main purpose of the individual has been the righteous behavior. This philosophy has been awakened by positive psychology paradigm today. The secret of the human mechanism is found strictly correlated with focusing on the individual strengths. Even when using his/her own signature, the individual's life satisfaction and happiness increase significantly (Şimşek, 2011). Focusing on weaknesses, the individual becomes unhappy and troubled. If virtual identity arouses negative or weak feelings as well as thoughts or behaviors, it is clear that identity will not support the 
individual. Given that, as a form of self-mediation, the congruence between the identities is recommended.

The nature will always provide the balance although technology tries to get dominant (Horkheimer, 2005). Many individuals with real life fears (i.e. fear of intimacy, fear of opening up, the fear of abandonment), use self-made virtual identities to overcome their fears. In the paradoxical intention mechanism, fears generate what is feared. Self-fulfilling prophecy is similar to this concept. Phobias and phobia symptoms wake during avoidance of fears. Results of psychoanalysis and psychology studies suggest that focusing on what is negative makes the individual not better. Turkle (2011) pointed out that those individuals who fear intimacy use technology-mediated communication more frequently than others.

Another way of building of a healthy identity is sufficient digital literacy. Immigrants moving to another country encounters language, culture, and identity problems. Similar to this situation, digital immigrants (Prensky, 2001) have disadvantages creating digital identity problems. The concept of Internet literacy, new literacies, digital literacyetc. refers to the skills necessary to cope with contemporary technologies in technical, cultural, psychological, ideological, and social arena. The older children and teens are relatively vulnerable due to being in the natural age of identity conflict in the real world. These temporary life crises affect the Internet life although they are usually accepted as digital natives. Therefore, digital literacies represent fundamental and critical skills for everyone in digital world (Şimşek \& Şimşek, 2013).

New literacies and digital citizenship skills are the concepts that will contribute to solving the challenge of identity-related problems of the virtual world. Literacies increase the awareness of the individual over identity conflicts. Jenkins, Clinton, Purushotma, Robinson, and Weigel (2006, p.4) categorized media literacies. Some of them include play, simulation, performance, appropriation, multitasking, distributed cognition, collective intelligence, judgment, trans media navigation, networking, and negotiation.

The term of digital citizenship skills, which refer to "the general norms of behavior with regard to appropriate technology use", is also related tothe concept of digital identity(Ribble, Bailey, \& Ross, 2004). Having an ideal virtual identity and acting with that identity in a 
responsible and ethical manner certainly include appropriate digital citizenship behaviors and corresponding norms. Individuals of the twenty-first century should be able to manage their multiple identities both in the physical world and virtual ecosphere which are inseparably connected through technology-mediated communication networks. 


\section{References}

Althusser, L. (2006). İdeoloji ve devletin ideolojik aygıtları. (Çev. A. Tümertekin). İstanbul: İthaki.

Arkonaç, S. A. (Ed.). (1993). Grup iliş̧kileri. İstanbul: Alfa.

Aslan, C. (2013). Toplumsalgruplar. İçinde A. Şimşek \& Ö. Eroğlu (Ed.), Davranışbilimleri (ss. 421-454). Konya: Eğitim.

Demirtaş, H. A. (2003). Sosyal kimlik kuramı. Iletişim Araştırmaları, 1(1), 123-44.

Elgin, V. M. (2007). Behavioral preferences, feelings, and social identity level in a low-status group: The impacts of social identity salience and group boundary permeability with a novel concept of hierarchical permeability (Unpublished master thesis).Ankara:

Middle East Technical University.

Erikson, E. H. (1980). Identity and the life cycle. New York: Norton.

Grohol, J. (2006). Anonymity and the online community identity matters. Retrieved 16 January 2013 from http://www.alistapart.com/articles/identitymatters.

Hogg, M. A. \& Abrams, D. (1988). Social identifications: A social psychology of intergroup relations and group processes. London: Routledge.

Horkheimer, M. (2005). Akıl tutulması. (Çev. O. Koçak). İstanbul: Metis.

Jenkins, H., Clinton, K., Purushotma, R., Robinson, A. J., \& Weigel, M. (2006). Confronting the challenges of participatory culture: Media education for the 21st century. Chicago, IL: The MacArthur Foundation.

Kress, G (2010). The profound shift in digital literacies. In J. Gillen \& D. Barton (Eds.),Digital literacies: A research briefing by the technology enhanced learning phase of the Teaching and Learning Research Programme. London: London Knowledge Lab, Institute of Education, University of London.

Lord, C. G., Ross, L., \& Lepper, M. R. (1979). Biased assimilation and attitude polarization: The effects of prior theories on subsequently considered evidence. Journal of Personality and Social Psychology, 37(11), 2098-2109.

McQuail, D. \& Windahl, S. (2005). Kitle iletişim çalışmalarında iletişim modelleri (Çev. K. Kumlu). İstanbul: İmge.

O'Reilly, T. (2009). What is Web 2.0: Design patterns and business models for the next generation of software. Retrieved 14 March 2012 from http://oreilly.com/pub/a/web2/ archive/what-is-web-20.html?page $=1$ 
Pearson, E. (2009). The performance of identity in online social networks. First Monday, 14(3), Retrieved 25 Fabruary 2012 fromhttp://firstmonday.org/htbin/cgiwrap/bin/ojs/ index.php/fm/article/viewArticle/2162/2127

Peffley, M., Avery, J. M., \& Glass, J. E. (2001, April). Public perceptions of bias in the news media: Taking a closer look at the hostile media phenomenon.Paper presented at the 2001 Meeting of the Midwest Political Science Association. Chicago, USA.

Posta Gazetesi (2012). Su perisi'ne mahkeme şoku: Internetten tanıştı̆̆ profesörü manken 'Yüksel Ak' olduğuna inandırarak para sızdıran 'Su Perisi Z' lakaplı kadın mahkemeye zorla getirilecek. Retrieved 19 October 2012 fromhttp://www.posta.com.tr/3Sayfa/ HaberDetay/-Su-perisi-ne-mahkeme-soku.htm? ArticleID=144802

Prensky, M. (2001). Digital natives, digital immigrants. On the Horizon, 9(5), 1-6.

Ribble, M. S., Bailey, G. D., \& Ross, T. W. (2004). Digital citizenship: Addressing appropriate technology behavior. Learning \& Leading with Technology, 32(1), 6-12.

Riley, J. W. \& Riley, M. W. (1959). Mass communication and the social system. In R. K. Meryon et al. (Eds.), Sociology today. New York: Basic Books.

Şimşek, E. (2011). Örgütsel iletişim ve kişilik özelliklerinin yaşam doyumuna etkileri (Yayınlanmamış doktora tezi). Eskişehir: Anadolu Üniversitesi Sosyal Bilimler Enstitüsü.

Şimşek, E., Özer, Ö., \& Şimşek, A. (2012). Haber kuramı bağlamında düşman medya etkisi: Basında yer alan futbolda şike haberlerinin farklı takımların taraftarlarınca algılanışı. İçinde Ö. Özer (Ed.), Haberin doğası: Gazetecilikte idealler ve sorunlar (ss.43-118). Konya: Literatürk.

Şimşek, E. \& Şimşek, A. (2013). New literacies for digital citizenship.Contemporary Educational Technology, 4(2), 126-137.

Tajfel, H. (1969). Cognitive aspects of prejudice. Human group and social categories: Studies in social psychology. Cambridge: Cambridge University Press.

Tajfel, H. (1981). Human groups and social categories: Studies in social psychology. Cambridge: Cambridge University Press.

Tajfel, H, Billig, M. G., Bundy, R. P., \& Flament, C. (1971). Social categorization and intergroup behaviour. EuropeanJournal of Social Psychology, 1, 149-77.

Tajfel, H.\& Turner, J. C. (1979). An integrative theory of intergroup conflict. In W. G. Austin \& S. Worchel (Eds.), The social psychology of intergroup relations (pp.33-47). Monterey, CA: Brooks/Cole. 
Turkle, S. (2011). Alone together: Why we expect more from technology and less from each other. New York: Basic Books.

Vitak, J. (2008). Facebook "friends": How online identity affects offline relationships? (Unpublished master's thesis). Georgetown University, Washington, DC.

Walters, K. P. (2010). An examination of the influence of primed characteristics of identity on motivation to learn conflict resolution skills (Unpublished doctoral thesis). Graduate School of the University of Oregon. 